\title{
Pengelolaan Neuroanestesi pada Pasien dengan Pentalogy of Fallot
}

\author{
Eka Satrio Putra, Retno Suryandari, Purwoko Purwoko, Ardana Tri Arianto \\ Departemen Anestesiologi \& Terapi Intensif Fakultas Kedokteran Universitas Sebelas Maret-RSUD Dr. \\ Moewardi Surakarta
}

\begin{abstract}
Abstrak
Pentalogy of Fallot (POF) salah satu jenis cacat jantung bawaan sianotik langka yang berpotensi tinggi komplikasi abses cerebri. Abses cerebri sering dijumpai pada kelainan jantung sianotik karena terjadinya hipoksia kronis dan yang kedua adalah hiperviskositas karena berkurangnya aliran mikrosirkulasi ke otak. Kami melaporkan seorang anak laki-laki berusia 6 tahun, berat badan $14 \mathrm{~kg}$ dengan abses otak multiple yang disertai dengan Pentalogy of Fallot (POF) yang akan dilakukan kraniotomi evakuasi abses. Pemeriksaan fisik preoperatif didapatkan GCS E4V5M6, $\mathrm{SpO}_{2}$ preductal $88 \%$, post ductal $84 \%$ dalam posisi supine. Pada sistem kardiovaskular didapatkan bunyi jantung I-II regular, bising sistolik terkuat di parasternal kiri ICS 3 grade 3, clubbing finger. Nilai hemoglobin 14,4gr\%, hematokrit $43 \%$, leukositosis $13,200 / \mathrm{mm}^{3}$ Tujuan anestesi pada penyakit jantung sianotik POF adalah menjaga curah jantung dengan mempertahankan denyut jantung, kontraktilitas juga preload, mencegah peningkatan rasio PVR:SVR serta menghindari hipersianosis akibat peningkatan mendadak kebutuhan oksigen sistemik. Pilihan agen anestesi harus didasarkan pada fisiologi pasien dan tujuan menyeimbangkan aliran darah paru dan sistemik. Rehidrasi yang adekuat sebelum induksi dan penggunaan diuretik manitol dapat dipertimbangkan mengingat hiperviskositas menurunkan pengiriman oksigen ke otak. Peningkatan TIK dari ketamine dapat dikurangi dengan hiperventilasi, kombinasi dengan benzodiazepin dan dengan pencegahan hipercapnia. Maka dari itu monitoring end tidal $\mathrm{CO}_{2}\left(\mathrm{ETCO}_{2}\right)$ perlu diperhatikan. Pengelolaan perioperatif pasien POF pada kasus evakuasi abses cerebri pada anak laki- laki usia 6 tahun pada laporan berikut ini menuliskan pentingnya pemahaman akan patofisiologi POF dan teknik neuroanestesi untuk mendapatkan luaran yang baik.
\end{abstract}

Kata kunci: Pentallogy of fallot, abses cerebri, perioperatif

JNI 2020, 9 (3): 168-72

\section{Neuroanesthesia on Patient with Pentalogy of Fallot}

\begin{abstract}
Pentalogy of Fallot (POF) is a rare type of cyanotic congenital heart defect with high risk of having cerebral abscesses as one of its complications. Cerebral abscesses are often found in cyanotic heart disease due to chronic hypoxia and hyperviscosity reduced microcirculatory flow to the brain. We report a 6-year-old boy, $14 \mathrm{~kg}$ body weight with multiple brain abscesses accompanied by Pentalogy of Fallot (POF) who undergone a craniotomy to evacuate the abscess. Preoperative physical examination found GCS E4V5M6, other vital signs within normal limits, preductal oxygen saturation $88 \%$, post ductal oxygen saturation in supine position $84 \%$. The I-II heart sounds are regular with grade 3 systolic murmur in the left parasternal third intercostal space and clubbing finger was found. The laboratory shows a hemoglobin value of $14.4 \mathrm{gr} \%$, hematocrit of $43 \%$, leukocytosis $13,200 / \mathrm{mm}^{3}$. The goal of anesthesia in cyanotic heart disease is to maintain cardiac output by stabilize heart rate, contractility as well as preload, prevent the increase of PVR:SVR ratio and avoid hypercyanotic due to sudden increase in systemic oxygen demand. The choice of anesthetic agent must be based on the patient's physiology. Adequate rehydration before induction and use of mannitol diuretics can be considered to reduce hyperviscosity that decrease oxygen delivery to the brain. Increased intracranial pressure from ketamine can be reduced by hyperventilation, in conjunction to benzodiazepines and prevention of hypercapnia. Therefore, monitoring end tidal $\mathrm{CO}_{2}\left(\mathrm{ETCO}_{2}\right)$ needs to be done. This case report delineating the perioperative management of a 6 years old boy with POF underwent evacuation of cerebral abscesses, will highlight the importance of understanding the pathophysiology of POF and neuroanesthesia techniques in order to receive a good outcome.
\end{abstract}

Key words: Pentalogy of fallot, cerebral abcess, perioperative

JNI 2020, 9 (3): 168-72

This article is licensed under a

Creative Commons Attribution-NonCommercial-ShareAlike 4.0 International License.

CEka Satrio Putra, Retno Suryandari, Purwoko Purwoko, Ardana Tri Arianto (2020)

under the CC-BY-NC-SA license 


\section{Pendahuluan}

Pentalogy of Fallot (POF) adalah suatu bentuk dari Tetralogy of Fallot (TOF) dengan tambahan atrial septal defect (ASD) selain adanya Ventricular septal defect (VSD), overriding aorta, obstruksi aliran arteri pulmonalis, hipertrofi ventrikel kanan. Jenis ASD yang paling umum ditemukan bersamaan dengan POF adalah ostium secundum (OS), diikuti oleh ASD primer. Kejadian TOF pada penyakit jantung bawaan adalah $10 \%$ dengan insiden 3 dalam 10000 kelairan hidup. Namun sampai saat ini masih belum ada laporan epidemiologis global tentang POF. ${ }^{1-3}$

Abses otak terbentuk akibat adanya pirau kanan ke kiri yang memotong proses filtrasi patogen pada kapiler paru merupakan potensi komplikasi noncardiac yang sering ditemukan pada penyakit jantung bawaan sianotik dengan angka kejadian 5-18\%. ${ }^{1,4,5}$ Faktor penyebab terbentuknya abses otak yang pertama adalah hipoksia karena bakteri anaerob adalah organisme yang paling sering ditemukan dari kultur abses dan yang kedua adalah hiperviskositas karena berkurangnya aliran mikrosirkulasi yang mengakibatkan infark mikro atau makro, ditambah sumber infeksi dalam aliran darah yang lambat membentuk cerebritis fokal diikuti oleh abses. ${ }^{2,4}$ Lobus parietal, frontal dan temporal adalah lobus yang paling umum untuk terjadinya abses otak. ${ }^{4,6}$

Hingga saat ini laporan kasus manajemen perioperatif pasien dengan POF yang belum dikoreksi masih sangat terbatas. Hal ini menjadi latar belakang penulis untuk dapat mengumpulkan data kasus lebih detail pada tatalaksana perioperatif pada pasien POF dengan rencana operasi pada sistem syaraf.

\section{Kasus}

\section{Anamnesis}

Seorang anak laki-laki berusia 6 tahun dengan berat badan $14 \mathrm{~kg}$ akan direncanakan untuk tindakan craniotomy drainase abses cerebri. Pasien mengeluhkan sakit kepala sejak 3 minggu sebelum masuk rumah sakit disertai batuk berdahak ringan. Riwayat sakit jantung dikenal sejak lahir, tidak ada pengobatan khusus.
Pemeriksaan Fisik:

Dari pemeriksaan fisik didapatkan GCS E4V5M6, tanda vital lain dalam batas normal. $\mathrm{SpO}_{2}$ preductal $88 \%$, post ductal $84 \%$ dalam posisi supine. Pada sistem kardiovaskular didapatkan bunyi jantung I-II regular, bising sistolik terkuat di parasternal kiri ICS 3 grade 3, clubbing finger.

\section{Pemerikasaan Penunjang}

Laboratorium menunjukkan nilai hemoglobin 14,4 gr\%, Hematokrit 43\%, leukositosis $13.200 / \mathrm{mm}^{3}$. Kesimpulan MRI kepala kontras menyebutkan adanya multiple abses cerebri disertai edema vasogenik luas di lobus temporoparietal kiri dengan herniasi subfalcine ke kanan sejauh $1 \mathrm{~cm}$. Echocardiografi menunjukkan ASD secundum diameter $0.8 \mathrm{~cm}$, VSD diameter $1,1 \mathrm{~cm}$ PMO overriding aorta, TR moderate $\mathrm{PG} 76,39 \mathrm{mmHg}$, AR mild dengan PHT 525 msec, PS severe dengan peak $\mathrm{PG} 87,86 \mathrm{mmHg}$.

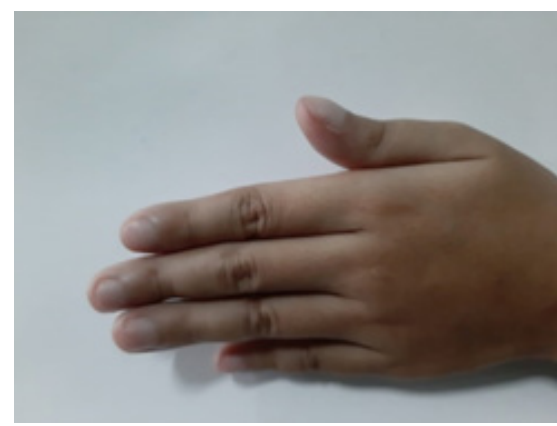

Gambar 1. Clubbing Finger

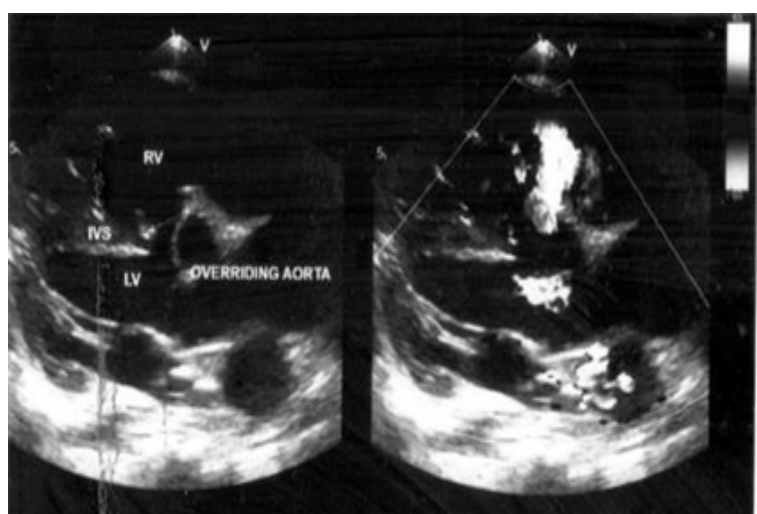

Gambar 2. Overriding Aorta 


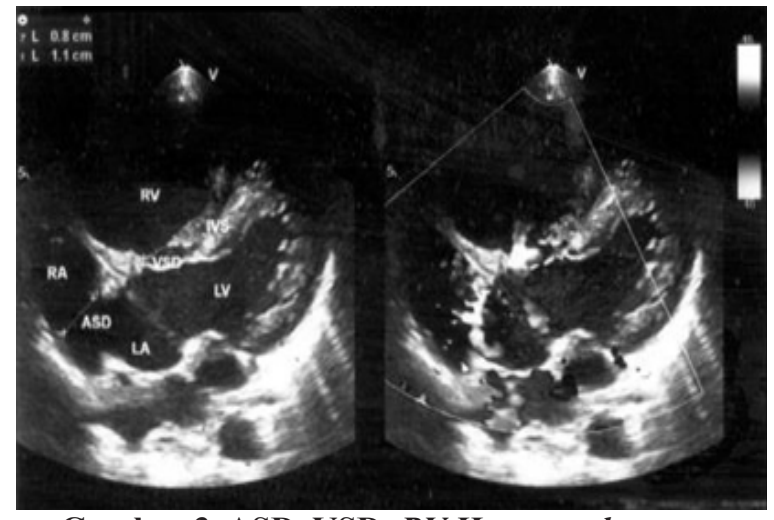

Gambar 3. ASD, VSD, RV Hypertrophy

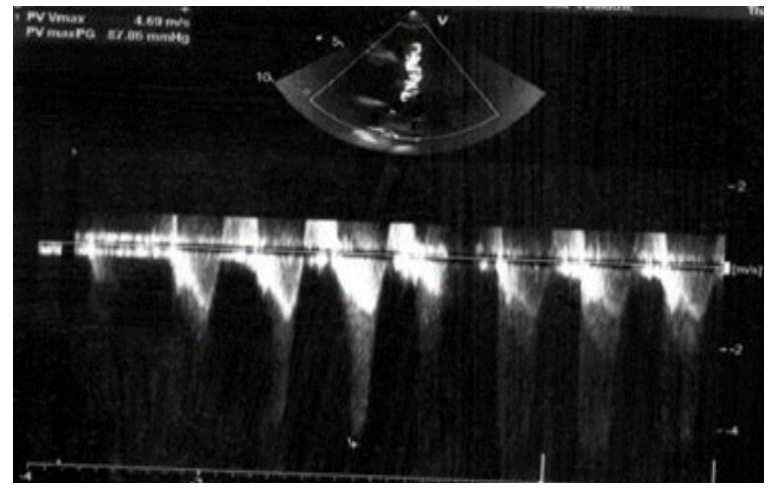

Gambar 4. Pulmonary Stenosis

Pengelolaan Anestesi

Setelah memperoleh persetujuan tindakan medis dari keluarga, pasien mendapat premedikasi intravena midazolam $0.05 \mathrm{mg} / \mathrm{kg}$ dan ketamin 1 $\mathrm{mg} / \mathrm{kg}$ sebelum dipisahkan dari keluarganya. Di kamar operasi, dilakukan pemasangan monitor standar sesuai rekomendari ASA. Didapatkan keadaan pasien dengan tekanan darah 95/62 mmHg laju nadi $100 \mathrm{x} /$ menit dan $\mathrm{SpO}_{2} 87 \%$. Sebelum dilakukannya induksi, pasien diberikan cairan kristaloid ringerfundin sebanyak $20 \mathrm{ml} /$ $\mathrm{kg}$. Analgesia fentanyl $1 \mathrm{mcg} / \mathrm{kg}$ intravena, induksi didalamkan dengan tambahan ketamin $1 \mathrm{mg} / \mathrm{kg}$ dan sevofluran $2 \mathrm{v} \%$ dalam $\mathrm{FiO}_{2} 80 \%$ berbanding airbar dengan hiperventilasi hingga dicapai $\mathrm{ETCO}_{2}$ 25-30 mmHg. Rocuronium 0.6 $\mathrm{mg} / \mathrm{kg}$ intravena diberikan sebagai pelumpuh otot sebelum dilakukan pemasangan pipa endotrakhea no. 3.5 non kinking. Monitoring invasive arterial line melalui iv canula no. 22 pada A. Radialis kanan dan CVP pada v. subclavia kanan. Foley catheter juga dipasang untuk memantau produksi urin.

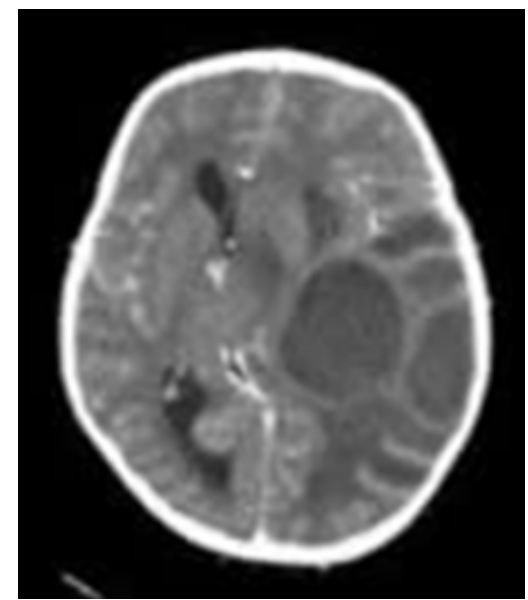

Gambar 5. Abses Cerebri Multipel

Anestesi dipelihara dengan ventilasi kontrol sevoflurane 1 vol\%dalam $50 \%$ oksigen berbanding airbar, fentanyl $1 \mathrm{mcg} / \mathrm{kg} / \mathrm{jam}$, rocuronium $10 \mathrm{mcg} / \mathrm{kg} / \mathrm{min}$ secara intravena kontinu. Pasien stabil selama operasi yang berlangsung selama4jamdengan denyutnadiberkisar90-100x/ menit, sistolik di kisaran 90-110 mmHg, $\mathrm{SpO}_{2} 90$ 94\% dengan $\mathrm{EtCO}_{2} 25-28$. Pendarahan sejumlah $150 \mathrm{ml}$ diganti dengan PRC. Setelah memastikan efek pelumpuh otot habis, pasien diekstubasi dalam kondisi sadar penuh 1 jam di ruang PICU.

\section{Pengelolaan pascabedah}

Pengelolaan pascabedah dengan analgesia ketamine $0,2 \mathrm{mcg} / \mathrm{kg} / \mathrm{jam}$ untuk 8 jam pasca operasi dan metamizole $20 \mathrm{mg} / \mathrm{kg}$ setiap 8 jam. Pada hari ketiga pasien dipindahkan ke bangsal dan diperbolehkan untuk rawat jalan pada hari ke-8.

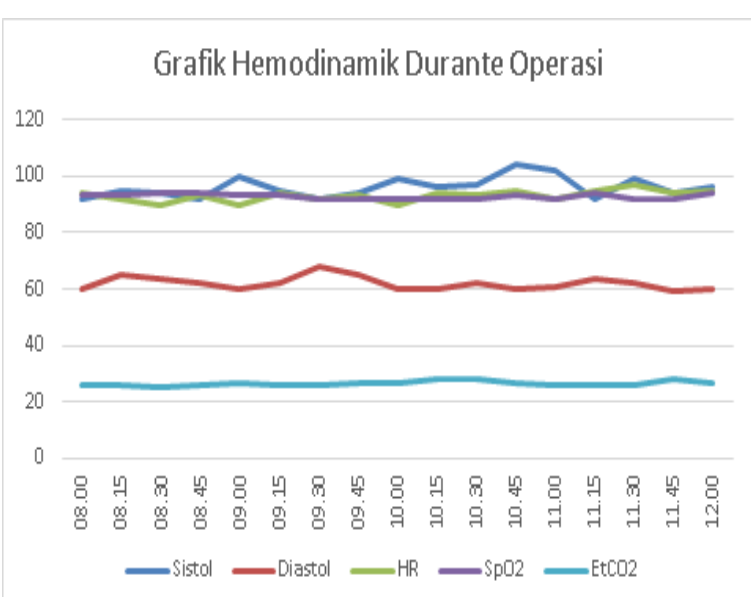

Gambar 7. Grafik Hemodinamik Durante Operasi 


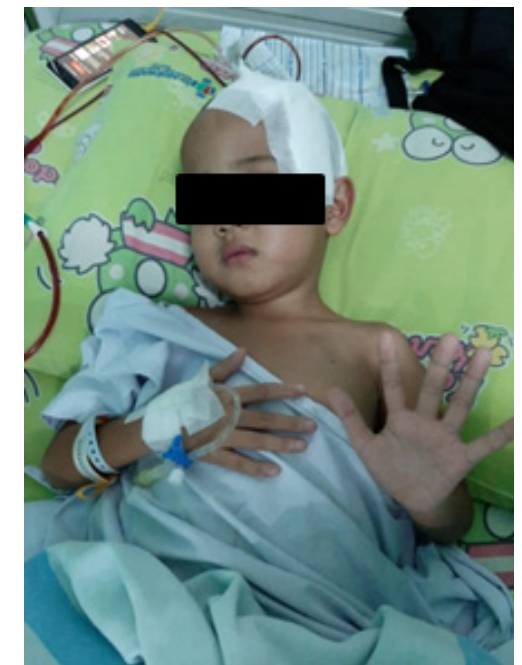

Gambar 7. Post Operasi Hari ke 5

\section{Pembahasan}

Tujuan anestesi pada penyakit jantung sianotik POF adalah menjaga cardiac output dengan mempertahankan denyut jantung, kontraktilitas juga preload, mencegah peningkatan rasio PVR:SVR serta menghindari hipersianosis akibat peningkatan mendadak kebutuhan oksigen sistemik seperti pada kondisi menangis, nyeri, tingkat anestesi yang tidak adekuat, kejang. ${ }^{1,2,4}$

Tindakan anastesi pada pasien dengan PJB sianotik dan pasien dengan abses otak menimbulkan sebuah pertanyaan yang menjadi dilema: "Bagaimana mencegah peningkatan PVR dan menjaga, bahkan sedikit meningkatkan SVR tanpa mempengaruhi tekanan intrakranial?". Menangisdapatmenyebakanhipoksiaberathingga "tet spel" dan peningkatan tekanan intrakranial. Hal ini dihindari dengan memberikan premedikasi sebelum memisahkan pasien dengan keluarganya. Pilihan agen anestesi harus didasarkan pada fisiologi pasien dan tujuan menyeimbangkan aliran darah paru dan sistemik. ${ }^{10,11}$ Ketamin memberikan efek menguntungkan pada anakanak dengan PJB dan hipertensi pulmonal berat dengan mempertahankan SVR dan kinerja ventrikel, tanpa meningkatkan resistensi vaskular paru. ${ }^{1}$ Efek serebral vasodilator dari ketamine dapat dikurangi dengan hiperventilasi, kombinasi dengan benzodiazepin dan diperberat dengan hipercapnia. ${ }^{12}$ Maka dari itu monitoring
End tidal $\mathrm{CO}_{2}\left(\mathrm{ETCO}_{2}\right)$ perlu diperhatikan. seringkali berada lebih jauh dibawah nilai tekanan alveoli $\mathrm{CO}_{2}$ dikarenakan adanya dead space yang lebih tinggi pada pasien dengan PJB sianotik terutama pada pasien lengan lesi jantung multiple dengan peningkatan aliran pirau. ${ }^{1,12,13}$ Hiperviskositas darah berakibat pada turunnya aliran darah otak. Rehidrasi yang adekuat sebelum induksi dan penggunaan diuretik manitol, serta penggantian darah penting dilakukan untuk mencegah memburuknya pirau kanan ke kiri dan demi menjaga tekanan perfusi otak yang memadai. Secara umum nilai hematocrit preoperasi dipertahankan untuk menjamin delivery oksigen yang adekuat. . $^{3,48}$

\section{Simpulan}

Pengelolaan perioperatif pasien POF yang menjalani operasi non kardiak khususnya bedah syaraf memerlukan pemahaman tentang patofisiologis POF dan teknik neuroanestesi untuk mendapatkan luaran yang baik.

\section{Daftar Pustaka}

1. Schmitz ML, Ullah S, Dasgupta R, Thompson LL, Andropoulos DB (Editor): Anesthesia for Right-sided Obstructive Lesions: Anesthesia for Congenital Heart Disease 3rd Edition. John Wiley \& Son New Jersey. 2015, 517524.

2. Marulasiddappa V, Raghavendra BS. Anesthesia for a rare case of uncorrected Pentalogy of Fallot undergoing craniotomy and drainage of brain abscess. Journal of Clinical and Diagnostic Research. 2015 Jul, Vol-9(7): UD01-UD02.

3. Singh SP, Chauhan S, Talwar S. Sinus venosus atrial septal defect in a patient with Pentalogy of Fallot. Ann Card Anaesth. 2012;15:166-68

4. Davis PJ dan Cladis FP. Smiths's Anesthesia for Infant and Children 9th Edition. Philadelphia: Elsevier, 2017, 1131-1333. 
5. Dilesh K, Cheran K, Kumar GG, Chandy IP. Anaesthetic management of Tetralogy of Fallot coming for non-cardiac surgery: a case report. Journal of Evolution of Medical and Dental Sciences. 2015;4(23):4029-32.

6. Sandhya K, Shivanna S, Tejesh CA, Rathna N. Labour analgesia and anaesthetic management of a primigravida with uncorrected Pentology of Fallot. Indian J Anaesth. 2012;56:186-88

7. Kalita N, Goswami A, Goswami P. Making pediatric neuroanesthesia safer. Journal Pediatric Neuroscience. 2017;12(4):305-312.

8. Pandian JD, Moosa NV, Cherian PJ, Radhakrishnan K. Brainstem abscess complicating tetralogy of Fallot successfully treated with antibiotics alone. Neurol India. 2000;48:272-75.
9. Bisri DY, Bisri T. Penatalaksanaan anestesi untuk drainase abses otak pasien dengan Tetralogi of Fallot. J Neuroanestesi Indonesia 2012;1(2):76-80.

10. Naqash I, Ahad B, Zargar J, Kirmani A, Wani M. Anaesthetic management of a case of Tetrology of Fallot for drainage of brain abscess: a case report. The Internet Journal of Anesthesiology. 2002;7(1).

11. Bisri DY, Bisri T. Dasar-dasar Neuroanestesi Edisi ke-4. Bandung: Fakultas Kedokteran Universitas Padjajaran, 2019; 7-28

12. Fazeli F, Baharvahdat H, Mashhadi S. Hypercyanotic spell after general anesthesia in Tetralogy of Fallot. The Internet Journal of Anesthesiology. 2006;13(1). 